\title{
Improving Strength of Expansive Soil using Coffee Husk Ash for Subgrade Soil Formation: A Case Study in Jimma Town
}

\author{
Yibas Mamuye $^{1}$ \\ Jimma University \\ Institute of Technology \\ Faculty of Civil and environmental Engineering \\ Jimma,Ethiopia
}

\author{
Anteneh Geremew ${ }^{2}$ \\ Jimma University \\ Institute of Technology \\ Faculty of Civil and environmental Engineering \\ Jimma,Ethiopia
}

\begin{abstract}
The economic back ground of Ethiopian mostly dependent of agricultural products. So that in the time of agricultural development production of large amount of wastes requires disposal. In order to reduce the disposal problem, utilization of waste in civil engineering works is very important aspect. Agricultural waste reuse has gained high momentum for achieving sustainable waste management in recent times. Keeping this view in mind this study has been carried out to assess utilization of coffee husk ash for improving expansive black cotton soil to utilize as a subgrade material for road construction. Hence experimental investigations have been made to study the suitability of coffee husk ash to improve properties of expansive soil. The important geo-technical properties test was Specific gravity, Liquid limit, Plastic limit, Plasticity index, dry density and California Bearing Ratio values. Expansive soil covers large portion of Ethiopia, covering nearly $40 \%$ surface area of the Country. Jimma town exhibits such kind of soil as a subgrade material. They are characterized by their nature of expansion or shrinkage upon changes in moisture content. According to ERA 2002 this type of soils is poor for subgrade construction. The laboratory work involved sieve analysis along with consistence test to classify the soil sample. The preliminary investigation of the soil shows that it belongs to A-7-5 class of soil in AASHTO and CH in USCS soil classification system. Soils under this class are generally of poor engineering use. Atterberg limits, compaction and CBR tests were used to evaluate properties of stabilized soil. The soil was stabilized with coffee husk ash in stepped concentration of $5 \%, 10 \%$, $15 \%, 20 \%$, and $25 \%$ by dry weight of the soil. Analysis of the results shows the addition of coffee husk ash improve the geotechnical properties of the expansive black cotton soil. The addition of Coffee husk ash reduces plasticity index, swelling and OMC with an increase in MDD and CBR with all increased coffee husk ash contents. The addition of $20 \%$ and $25 \%$ of coffee husk ash established an increased CBR value by $252 \%$ and $296 \%$ respectively, indicating the subgrade class falling under S3. From this study it was found out that coffee husk ash stabilized soil do meet the minimum requirement of ERA pavement manual specification for use as a sub-grade material in road construction. Agricultural waste like coffee husk Ash have significant potential to be used in place of conventional material for various road constructions and should be projected for future construction.
\end{abstract}

Keywords: - Expansive soil, stabilization, coffee husk ash, subgrade formation, CBR value

\section{INTRODUCTION}

\subsection{Background}

The stability of the structures to be built on the soil depends totally on the stability of the soil at which it rests so that Soil is the basic for any construction, it supports the substructure of any structure and it is the subgrade which supports the sub base/base in the pavement. There are several soils that pose threat to the stability of the structures because of the existing soil at a particular location may not be suitable for the construction due to poor bearing capacity and higher compressibility or even sometimes excessive swelling in case of expansive soils. This type of soil poses severe problem on construction activities; which can lead to expensive design, construction cost, mitigation measure as well as repeated and costly maintenance cost [4].

Expansive soils are clay soils with high plasticity commonly which are black or gray in color. They are characterized by their nature of expansion or shrinkage upon changes in moisture content. Foundations constructed on these clays are subjected to large up lifting forces caused by the swelling. These forces will induce heaving, cracking, and breakup of different structures. Most of structural damages due to expansive soils result from the differential rather than the total movement of the foundation soil as a result of swell. Damage can occur within a few months following construction, may develop slowly over a period of few years, or may not appear for many years until some activity occur to disturb the soil moisture equilibrium. Expansive soils are distributed very widely over almost all geographical locations in the world, causing distress to the structures founded on them and discomfort to the users [12].

Expansive soil covers large portion of Ethiopia, covering nearly $40 \%$ surface area of the Country [8]. Especially Jimma zone are mainly covered with expansive and black cotton soils which has surface and subsurface water which mostly encloses the flat area. For this reason, constructions could be sensitive for structural failure as a result of excessive consolidation settlement [3].

The improvement of problematic soil at a site is indispensable due to rising cost of the land, and there is huge demand for road construction. There is a need to 
concentrate on improving properties of soils using costeffective practices like treating it with low cost and easily available material.

There are several treatment methods for improving properties of problematic soil; among this Stabilization is one of the most common methods. Soil stabilization is the process of altering the properties of a soil by applying some modifiers to meet specified Engineering requirements of road pavement layers. It can be taken as alternate to borrow selected materials and it has advantage that the effect to the environment is reduced and in areas where selected/granular materials are scarce, it has comparative economic advantage [1].

Soil stabilization is carried out by various methods and one of them is mixing with the Stabilizing Additives such as lime and cement. The demand of lime and cement has been increasing in the construction industry which causes increasing their cost. Efforts therefore have been carried out since long time to use the materials as admixtures which are obtained as waste from the agricultural waste. The processing of coffee generates significant amounts of agricultural waste, ranging from $30 \%$ to $50 \%$ the weight of the total coffee produced, depending on the type of processing. Coffee husks are the major solid residues from the processing of coffee, for which there are no current profitable uses, and their adequate disposal constitutes a major environmental problem [2].

Along the several steps of coffee production (from the small producers to the big companies of coffee processing and roasting) a huge amount of residues is generated. For instance, in Brazil the production of coffee from 2008 to 2013 averaged 2.9 million tons, being generated about 1.4 million tons of wastes each year [2].

In this study, agricultural wastes like coffee husk ash had been used to improve geotechnical properties of a soil. Ethiopia produces a large volume of coffee beans every year, around 450,000 tons during 2013/2014 alone [9].Coffee husk is a byproduct of coffee. The main objective of this study is to investigate the potential application of coffee husk as stabilization material specifically for road construction.

\subsection{Statement of the Problem}

Expansive soils are clay soils that contain clay mineral called Montmorillonite. Such soils are capable of absorbing great amount of water and expand. The expansive nature of the clay is less near the ground surface where the profile is subjected to seasonal and environment changes. The more water they absorb the more their volume increases. Expansive soils also shrink when they dry out. Fissures in the soil can also develop. These fissures help water to penetrate to deeper layers. This produces a cycle of shrinkage and swelling that causes the soil to undergo great amount of volume changes. This movement in the soil results in structural damages especially in lightweight structures such as one or two story buildings, warehouses, retaining walls, sidewalks, driveways, basement floors, pipelines and foundations[6].

Every Civil Engineering structure is to be founded on soil. The soil on which the structure is to be built should be capable of withstanding the load to be imposed on it However, naturally there exist problematic soils to be used as foundation or subgrade materials, such as soil with poor bearing capacity and higher compressibility or even sometimes excessive swelling in case of expansive soils whose engineering characteristics are mainly affected by fluctuation of moisture content. Many damages occur each year and roads constructed on such soils exhibit serious problems including increased cost of construction and maintenance. Jimma town exhibits such kind of soil as a subgrade material [3]. Expansive soil is a problem in Ethiopia as in other countries. To deal with it, there are different methods of altering the nature of this soil to make it fit for construction; stabilization using certain agricultural and domestic wastes is one of them.

Soil Stabilization is being used for a variety of engineering works, the most common application being in the construction of road and pavements, where the main objective is to increase the strength or stability of expansive soil and to reduce the construction cost by making best use of the locally available materials. Thus the use of Agricultural waste (such as rice husk ash -RHA, coffee husk ash - CHA) will considerably reduce the cost of Construction and as well reducing the environmental hazards they cause [14]. Since Ethiopia has coffee beans production every year, around 450,000 tons is produced during 2013/2014 alone [9]. Coffee production is high in Jimma zone. Therefore, it has a low cost to use as a stabilizer. Jimma Zone is one of coffee growing zones in the Oromia Regional State, which is produced in the eight woredas namely, Gomma, Manna, Gera, Limmu Kossa, Limmu Seka, Seka Chokorsa, Kersa and Dedo which has a total area of 1,093,268 hectares of land Currently, the total area of land covered by coffee in the zone is about 105,140 hectares, which includes small-scale farmers' holdings as well as state and private owned plantations. Out of the 40 55 thousand tons of coffee annually produced in the Zone [13].

The processing of coffee generates significant amounts of agricultural waste, ranging from $30 \%$ to $50 \%$ the weight of the total coffee produced, depending on the type of processing. Coffee husks are the major solid residues from the processing of coffee, for which there are no current profitable uses, and their adequate disposal constitutes a major environmental problem [15].

Therefore, the research study identifies the suitability of using coffee husk ash to improve the engineering property of expansive soil of Jimma town to use as sub grade material for road construction. To achieve the objectives of the research study, a review of related literatures, organization of input data and laboratory implementation for analysis is undertaken

\subsection{Objectives}

\subsubsection{General Objective}

The main objective of this study is to improve strength of expansive soil using coffee husk ash for sub- grade formation 


\subsubsection{Specific Objectives}

- To determine the engineering property of expansive soil from Jimma town.

- To analyze the change in properties of stabilized expansive soil when blended with coffee husk ash.

- To compare laboratory test result with ERA standard specification.

\subsection{Scope of the study}

The study covers stabilization of expansive black cotton soil using coffee husk ash in Jimma town; it is supported by different types of literatures and a series of laboratory experiments, the relevant laboratory tests will be grain size distribution (gradation), standard Proctor compaction, CBR and Atterberg limit taste. However, the findings of the

\subsection{Study Design}

Experimental study designs were used in this study. It was attempted to conducted laboratory tests sieve analysis, Atterberg limits, Specific gravity, CBR value, and Standard research are limited on expansive black cotton soil in Jimma town.

\section{MATERIALS AND RESEARCH METHODOLOGY}

\subsection{Study Area}

Jimma was located at about $354 \mathrm{~km}$ in Southwest of Addis Ababa (GSE, 2012). The Geographical condition of the town approximately $7^{\circ} 41^{\prime} \mathrm{N}$ Latitude and $36^{\circ} 50^{\prime} \mathrm{E}$ Longitude. The town has a temperature of $20-30^{\circ} \mathrm{C}$ with an average annual rainfall $800-2500 \mathrm{~mm}$. The town was found in an area of the altitude of $1718-2000 \mathrm{~m}$ above sea level. It lies in the climatic zone locally known as Woynā Dagā which is considered ideal for agriculture as well as human settlement [10].

Proctor compaction tests on virgin soil samples and treated samples with different proportion of Coffee Husk Ash and checking to standard specification.

The flow chart of the research is showing as follows

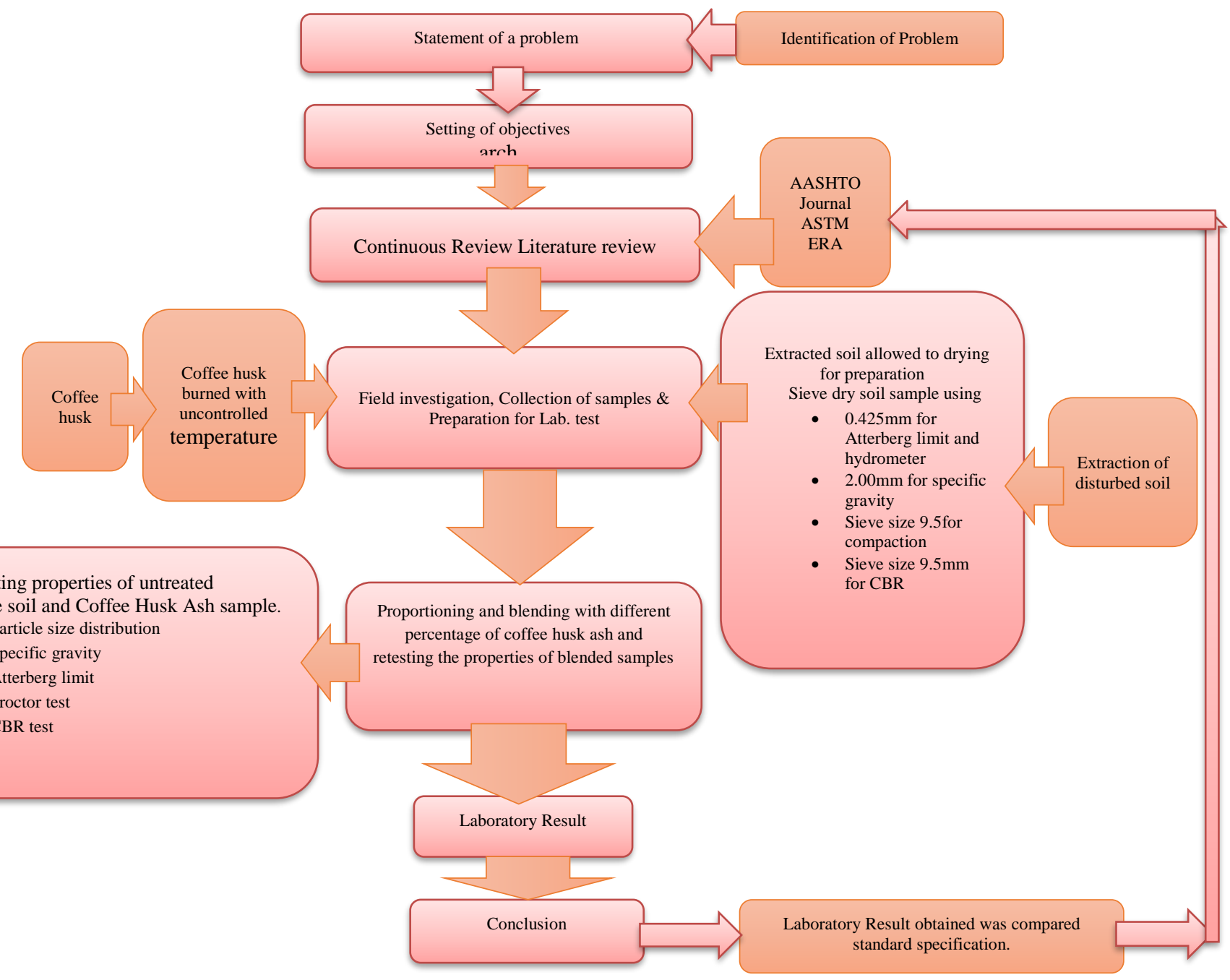

Figure 2.1 Research design diagram 


\subsection{Data source and collection}

During data collection, data were collected from primary and secondary source. Primary data where obtained by laboratory tests and secondary data's are literature and materials used for this research from different source.

\subsection{Material source}

\subsubsection{Expansive soil}

The soil sample used in this study was expansive black cotton soil, which is collected from Jimma town. The soil sample which represents an expansive soil of Jimma town was collected based on previous study conducted by Nurela M. (2018). According to Nurela M. (2018), expansive black cotton soils highly occur in Jimma town in Ginjo Guduru or Kebele 5. A disturbed sample was collected from the pit at a depth of $1.5 \mathrm{~m}$ from ground level in order to avoid the inclusion of organic matter.

\subsubsection{Coffee Husk Ash}

The coffee husk was collected from local shop from Jimma town in the form of husk which was solid waste. Coffee Husk Ash was obtained from burning of the coffee husk in uncontrolled condition. After complete burning, the ash where allowed to cool for another 24 hours.

\subsection{Sampling Techniques}

The sampling technique used for this research was a purposive sampling which is non - probability method. This sampling technique was proposed based on the information that to determine the strength of the expansive soil.

\subsection{Study variable}

\subsubsection{Independent variable}

Independent variables of this research was

- Dosage of coffee husk ash,

- Plastic limit, liquid limit, MDD, OMC and CBR of unblended and blended expansive soil.

\subsubsection{Dependent variable}

Effect of Coffee Husk Ash on expansive subgrade

soil

\subsection{Methods and standard testing procedure}

Standards and specifications for this study were adapted from AASHTO, ASTM and IS.

Table 2. 1 Standards and Specification for this Study

\begin{tabular}{|l|l|l|l|}
\hline \multirow{2}{*}{ No. } & \multicolumn{1}{|c|}{ Laboratory tests } & \multicolumn{2}{c|}{ Standards } \\
\cline { 3 - 4 } & & AASHTO & ASTM \\
\hline $\mathbf{1}$ & Moisture Content & T265 & \\
\hline $\mathbf{2}$ & Grain Size Analysis & & D422-63 \\
\hline $\mathbf{3}$ & Atterberg Limits & & D4318-98 \\
\hline $\mathbf{4}$ & Soil Classification & & D2487-98 \\
\hline $\mathbf{5}$ & Specific Gravity & D854-83 \\
\hline $\mathbf{6}$ & Standard Proctor Compaction & & D698-98 \\
\hline $\mathbf{7}$ & CBR & T193-93 & \\
\hline
\end{tabular}

\subsection{Sample Preparation}

Before treating and testing, the sample was prepared in accordance with the described AASHTTO T87-86. This method includes:

$\checkmark \quad$ Air and oven dried the samples.

$\checkmark$ Preparing uniform samples for Atterberg Limits, Compaction and Californian bearing ratio tests.

$\checkmark \quad$ Mixing soil and coffee husk ash manually to get uniform mix for each test.

\section{RESULT AND DISCUSSION}

\subsection{Engineering properties of untreated expansive soil} The tests involved to identify the properties of the soil such as its physical and mechanical properties. The tests carried out on the untreated expansive soil include sieve analysis, Atterberg limit test, compaction test, California bearing ratio and specific gravity. Based on consistency and particle size distribution of virgin sample, soil classification was conducted as per AASHTO and Unified soil classification system. Engineering properties of the untreated expansive soil was shown in Table 3.1 below.

Table 3. 1 Geotechnical Properties of Untreated Expansive Soil

\begin{tabular}{|c|c|c|}
\hline Sr. No. & Property & Observed Values \\
\hline 1 & \multicolumn{2}{|c|}{ Classification } \\
\hline & AASHTO (group index) & A-7-5 \\
\hline & USCS group symbol & $\mathrm{CH}$ \\
\hline & USCS group name & Highly Plastic Clay \\
\hline 2 & Specific gravity & 2.6 \\
\hline 3 & \multicolumn{2}{|c|}{ Particle size analysis } \\
\hline & Gravel content\% (20 to $4.75 \mathrm{~mm})$. & 0.588 \\
\hline & Sand content $\%$ (4.75 to $0.075 \mathrm{~mm}$ ) & 5.514 \\
\hline & $\begin{array}{l}\text { Silt and clay content } \% \text { (below } \\
0.075 \mathrm{~mm} .)\end{array}$ & 93.898 \\
\hline 4 & \multicolumn{2}{|c|}{ Atterberg's Limits: \% } \\
\hline & Liquid limit & 88.65 \\
\hline & Plastic limit & 32.37 \\
\hline & Plasticity index & 56.28 \\
\hline 5. & \multicolumn{2}{|l|}{ Proctor test } \\
\hline & $\begin{array}{c}\text { Optimum moisture content (OMC), } \\
\%\end{array}$ & 35.80 \\
\hline & Maximum dry density $\left(\mathrm{g} / \mathrm{cm}^{3}\right)$ & 1.26 \\
\hline 6. & CBR value \% (Soaked) & 1.5 \\
\hline
\end{tabular}

\subsection{Properties of Coffee Husk Ash}

The main focus of this study was utilization of coffee husk for road construction to improve the properties of expansive soil and to increase economic and environmental benefits. The coffee husk was collected from local shop and burnt in uncontrolled condition. After the coffee husk was burned in uncontrolled condition were cooled for 24 hours. Specific gravity, liquid limit, plastic limit and sieve analysis tests were conducted. The physical property of the CHA is tabulated in Table 3.2 below. 


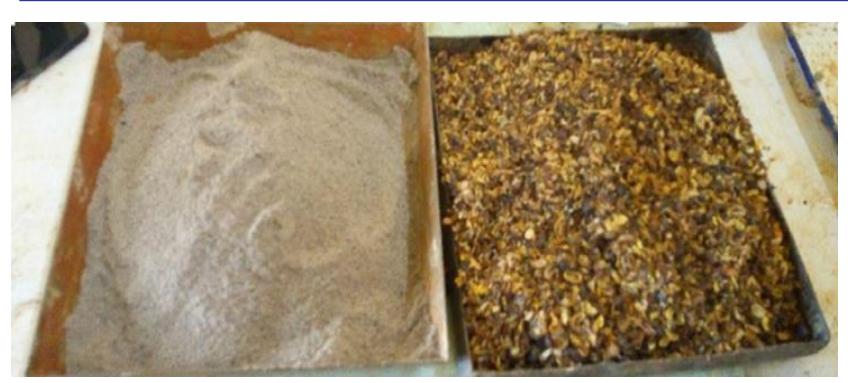

Figure 3.1 Coffee Husks and CHA

Table 3.2 Properties of CHA

\begin{tabular}{|c|c|c|}
\hline \multicolumn{2}{|c|}{ Properties } & $\begin{array}{c}\text { Observed } \\
\text { Values }\end{array}$ \\
\hline \multirow{3}{*}{ Particle Size Gradation } & Gravel \% & 0 \\
\cline { 2 - 3 } & Sand \%, & 78.9 \\
\cline { 2 - 3 } & Fine \% & 21.90 \\
\hline \multirow{2}{*}{ Consistency } & Liquid limit, \% & 28.26 \\
\cline { 2 - 3 } & Plastic limit, \% & 27.70 \\
\cline { 2 - 3 } & Plastic index, \% & 0.99 \\
\hline \multicolumn{2}{|c|}{ Specific gravity } & 2.54 \\
\hline
\end{tabular}

\subsection{Engineering properties of treated expansive soil}

\subsubsection{Effect of CHA on Atterberg limit}

The effect of CHA in varying proportion with expansive soil had been studied and the variation in consistency limits for various mixes was presented in Table 3.3. It is found that as the percentage of CHA increases the liquid limit decrease and plastic limit increases up to $15 \%$ of $\mathrm{CHA}$ and decrease after $15 \%$ of CHA Consequently the plasticity index decreased followed with increase in CHA content. Table 3.3 Effect of Diffrent percentage of CHA on Atterberg's

Limit

\begin{tabular}{|c|c|c|c|c|}
\hline Symbol & $\begin{array}{c}\text { Liquid } \\
\text { Limit, \% }\end{array}$ & $\begin{array}{c}\text { Plastic } \\
\text { Limit, \% }\end{array}$ & $\begin{array}{c}\text { Plasticity } \\
\text { Index, \% }\end{array}$ & $\begin{array}{c}\text { Swelling } \\
\text { Potential }\end{array}$ \\
\hline NS & 88.65 & 32.37 & 56.28 & $\begin{array}{c}\text { Very } \\
\text { high }\end{array}$ \\
\hline NS+5\%CHA & 84.84 & 37.89 & 46.95 & High \\
\hline NS+10\%CHA & 82.29 & 41.48 & 40.81 & High \\
\hline NS+15\%CHA & 76.42 & 43.57 & 32.86 & Medium \\
\hline NS+20\%CHA & 61.01 & 33.84 & 27.17 & Medium \\
\hline NS+25\%CHA & 55.87 & 30.11 & 25.76 & Medium \\
\hline
\end{tabular}

From Table 3.3 plastic index had improved through the addition of different proportion of CHA. According to Chen F.H. the addition of CHA has improved the swelling potential from very high to medium. The untreated expansive soil plasticity index values determined in laboratory were $56 \%$. The addition of $5 \%, 10 \%, 15 \%, 20 \%$, and $25 \%$ CHA improved the untreated expansive soil plasticity index by $16.6 \%, 27.5 \%, 41.6 \%, 51.7 \%$ and $54.2 \%$ respectively

\subsubsection{Effect of CHA on compaction Test}

The Standard Proctor's test was performed for the expansive soil with different CHA percentages and presented in Figure 3.2. The values for the maximum dry densities were noted to significantly increase with the addition of CHA from a neat value of $1.26 \mathrm{~g} / \mathrm{cm}^{3}$ to a maximum value of $1.41 \mathrm{~g} / \mathrm{cm}^{3}$ attained in the blend $25 \%$
CHA. The OMC was found to decrease from $35.8 \%$ $29.6 \%$.

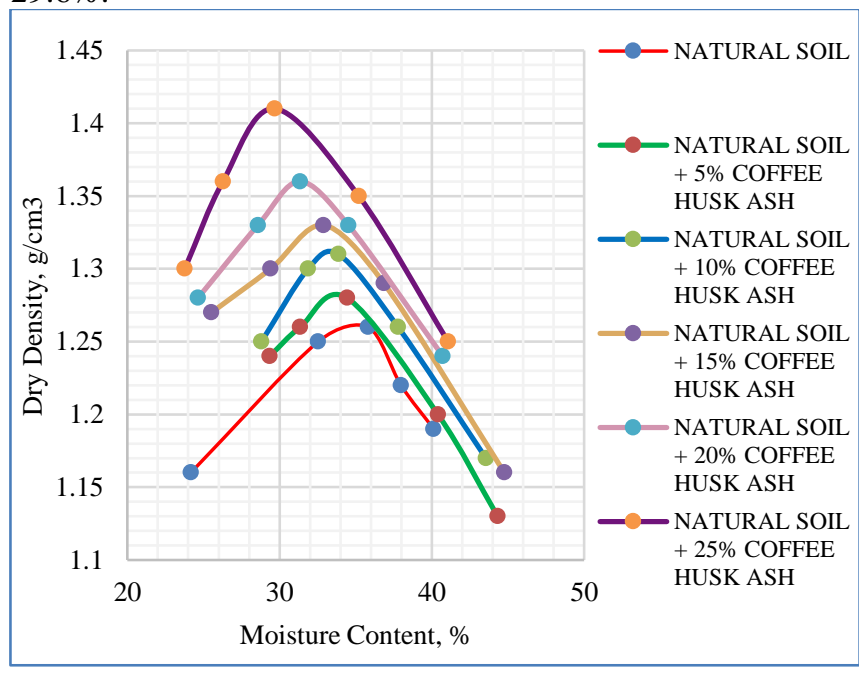

Figure 3.2 Effect of Different percentage of CHA on Standard Proctor Test

The effect of CHA on the MDD content for the soil was shown in figure 3.3. The MDD for different percentage of $\mathrm{CHA}$ increased as the percentage of CHA increased from $1.59 \%$ to $11.9 \%$. The maximum dry density for the natural soil is $1.26 \mathrm{~g} / \mathrm{cm}^{3}$, in the process of stabilizing the expansive black cotton soil the addition of $5 \%, 10 \%, 15 \%$, $20 \%$ and $25 \%$ CHA increased the maximum density as $1.28 \mathrm{~g} / \mathrm{cm}^{3}, 1.31 \mathrm{~g} / \mathrm{cm}^{3}, 1.34 \mathrm{~g} / \mathrm{cm}^{3}, 1.36 \mathrm{~g} / \mathrm{cm}^{3}$ and 1.41 $\mathrm{g} / \mathrm{cm}^{3}$ respectively.

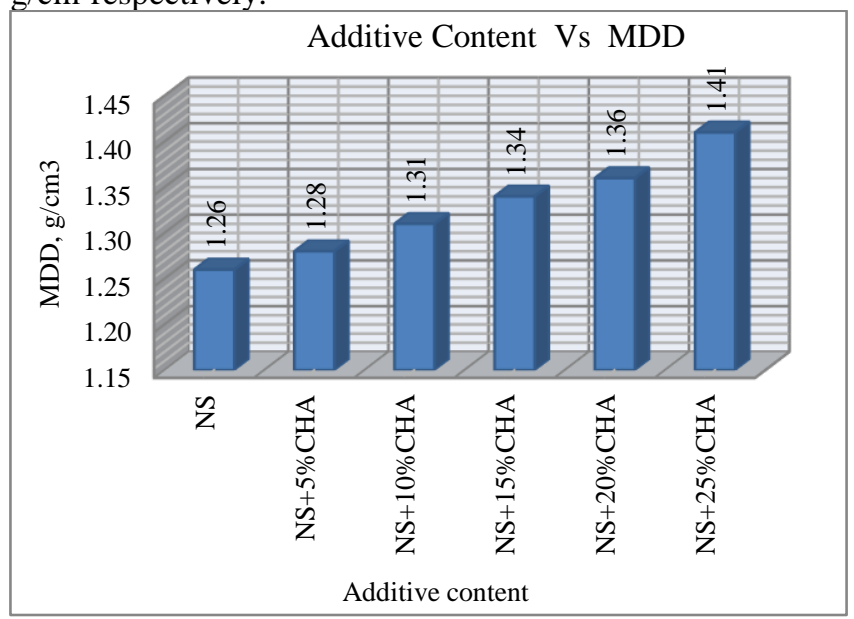

Figure 3.3 Effect of CHA on MDD

The effect of CHA on the optimum moisture content for the soil was shown in figure 3.4. The optimum moisture content for different percentage of $\mathrm{CHA}$ decreased as the percentage of CHA increase from $4.3 \%$ to $17.09 \%$. The OMC for the natural soil was 35.8 ; in the process of stabilizing the expansive black cotton soil the addition of $5 \%, 10 \%, 15 \%, 20 \%$ and $25 \%$ CHA decreased the OMC as $34.25,33.60,32.65,31.34$ and 29.68 respectively. 


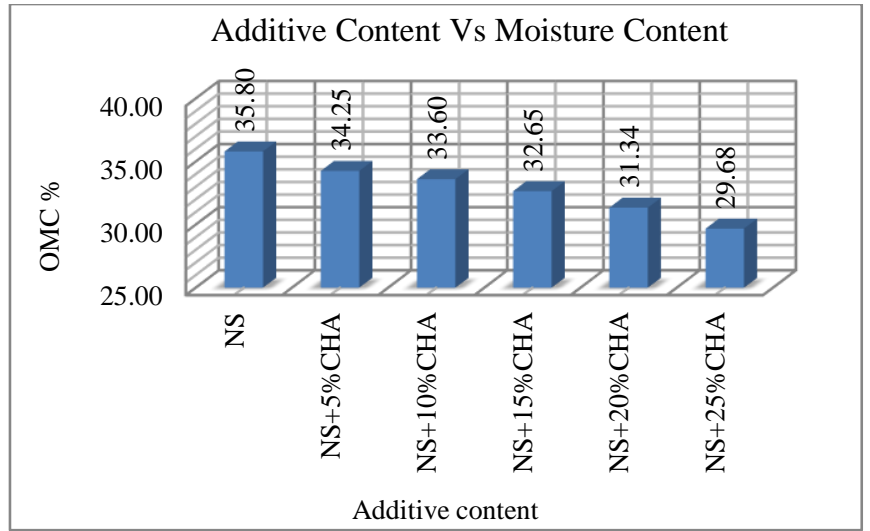

Figure 3.4 Effect of CHA on OMC

\subsubsection{Effect of CHA on CBR and Swell Test}

When treating the expansive soil at different percentage of CHA, the CBR value increased while the swell decreased significantly.

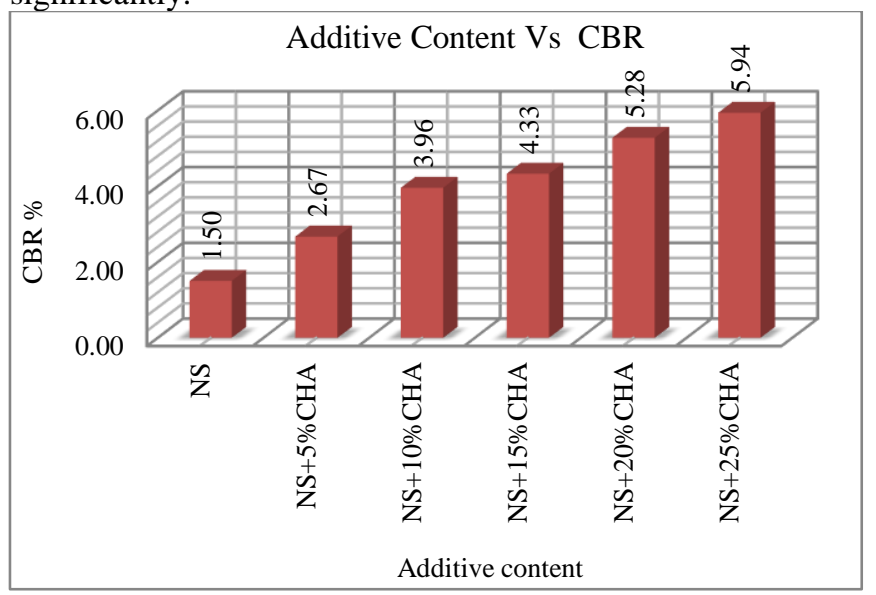

Figure 3.5 Effect of CHA on CBR Value

The CBR for the natural soil was $1.5 \%$, indicating very poor quality. The addition of $5 \%, 10 \%, 15 \%, 20 \%$ to $25 \%$ CHA increased the CBR by $78 \%, 164 \%, 188 \%, 252 \%$ and $296 \%$ respectively. This shows that the strength of the black cotton soil increased with an increase of percentage of CHA. According to ERA 2002 the subgrade class for the natural soil and natural soil blended with different percentage of CHA is tabulated in the Table 3.4.

Table 3.4 Subgrade class of soil with CHA

\begin{tabular}{|c|c|}
\hline Additive Content & Subgrade Class \\
\hline Natural Soil & S1 \\
\hline Natural Soil + 5\% Coffee Husk Ash & S2 \\
\hline Natural Soil + 10\% Coffee Husk Ash & S2 \\
\hline Natural Soil + 15\% Coffee Husk Ash & S2 \\
\hline Natural Soil + 20\% Coffee Husk Ash & S3 \\
\hline Natural Soil + 25\% Coffee Husk Ash & S3 \\
\hline
\end{tabular}

According to ERA 2002 site investigation manual, a material with CBR value less than 2 are very difficult to work and subgrade would lead to uneconomical pavement structure, its recommended to cover with selected material or treating it with other stabilizing material. Therefore, the soil requires initial modification and/or stabilization to improve its workability and engineering property. Therefore, the addition of $20 \%$ and $25 \%$ of CHA modifies the soil to a suitable subgrade material for pavement construction.

The swell value of the natural soil decreased with an increase of CHA, as indicated on figure 3.6.

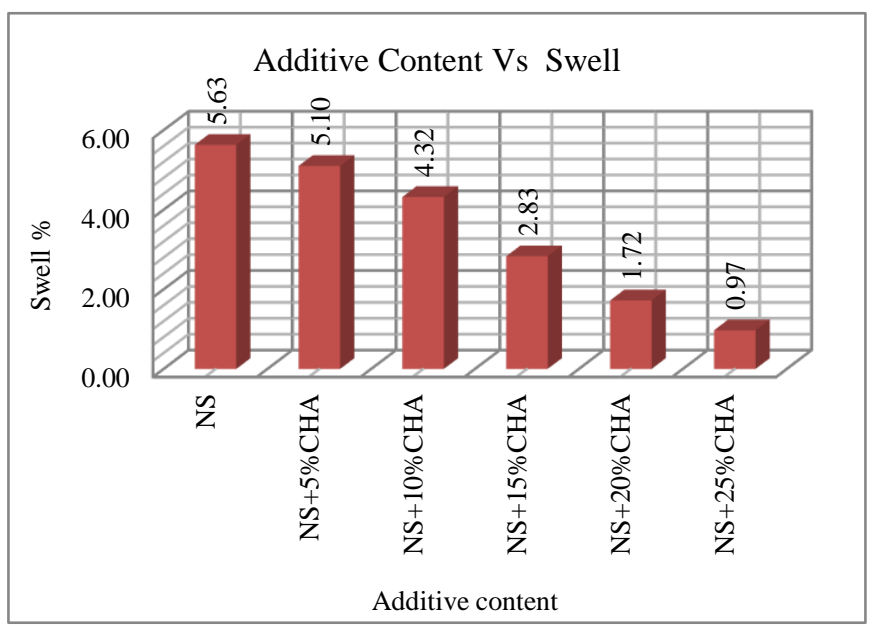

Figure 3.6 Effect of CHA on Swelling Tendency

The swell value for different percentage of CHA decreased as the percentage of CHA increased. The swell value for CHA of 5\%, 10\%, 15\%, 20\% and $25 \%$ increased by $9.41 \%$, $23.27 \%, 49.73 \%, 69.5 \%$ and $82.77 \%$ respectively. A decrease in swelling potential due to anticipated moisture indicates the soil resistance for volume instability decreases.

\subsection{Result Summery}

The natural expansive black cotton soil exhibits an engineering property of specific gravity having a value of 2.6, soil classification of A-7-5 according to ASSTHO, a plastic index of 56.28 and a low CBR value of 1.5 which indicates the soil to be poor for engineering use. Therefore, it needs modification.

The addition of CHA modified the engineering property of the soil to a suitable material for subgrade construction. The effect of the addition of a stepped value of $5 \%, 10 \%$, $15 \%, 20 \%$ and $25 \%$ CHA modified the value of the engineering properties investigated in this research. The plastic index decreased from $16.6 \%$ to $54.2 \%$, the MDD increased from $1.59 \%$ to $11.9 \%$ while OMC decreased from $4.3 \%$ to $17.09 \%$, and the CBR value increased from $78 \%$ to $296 \%$ while the swell decreased by $9.41 \%$ to $82.77 \%$.

According to ERA manual, the addition of $20 \%$ and $25 \%$ of CHA changed the subgrade class of the natural soil from $\mathrm{S} 1$ to $\mathrm{S} 3$. This makes the natural soil suitable material for utilization as subgrade construction material.

\section{CONCLUSIONS AND RECOMMENDATIONS}

\subsection{Conclusion}

On the basis of the results obtained in the experimental investigation, the following conclusions have been drawn. 
The natural subgrade soil of the subject area was generally classified as a material of poor engineering property to be used as a sub-grade material, it requires initial modification and/or stabilization to improve its workability and engineering property.

$>$ The addition of CHA in natural expansive soil, the value of liquid limit increased and plastic limit increased until $15 \%$ of CHA and decreased after $15 \%$ CHA, leading the plasticity index of stabilized natural expansive soil to reduce.

$>\quad$ The values for the maximum dry densities were noted to significantly increase with the addition of CHA and the OMC was found to decrease.

$>$ According to ERA 2002 site investigation manual, a material with CBR value less than 2 are very difficult to work and subgrade would lead to uneconomical pavement structure, its recommended to cover with selected material or treating it with other stabilizing material. The natural soil has CBR value of 1.5. Therefore, the soil requires initial modification and/or stabilization to improve its workability and engineering property.

$>$ The addition of $20 \%$ and $25 \%$ of $\mathrm{CHA}$ modifies the soil to a suitable subgrade material for pavement construction increasing the value of CBR by $252 \%$ and $296 \%$. The subgrade class of the stabilized soil by $20 \%$ and $25 \%$ falls under the class of S3.

Generally, natural soil and treated expansive soil properties were computed based from laboratory test results. Each observed values were presented according to the requirements of ERA standard specifications. Based on the laboratory result the natural soil did not satisfy the requirements of ERA standard specifications for subgrade construction. However, after blending with $20 \%$ and $25 \%$ CHA, the mix proportion satisfied ERA standard specifications for subgrade construction.

\section{Recommendation}

> Agricultural waste like coffee husk Ash has significant potential to be used in place of conventional material for various road constructions and should be projected for future construction.

$>$ Further studies in the addition of CHA should be carried out in order to find out the effect that $\mathrm{CHA}$ has on different types of soils and under different exposure conditions.

$>$ Further studies should be carried out in order to identify the long term effects that CHA has on the durability of the road pavement structures.
$>$ Further studies should be made on chemical composition of coffee husk ash.

\section{REFERENCES}

[1] T. Sherwood, And M.D. Ryley (1966), "The Use of Stabilized Pulverized Fuel Ash in Road Construction," Road Research Laboratory, Rrl Report No. 49, Crowt Horne.

[2] Leandro Soares Oliveira And Adriana S Franca, An Overview Of The Potential Uses For Coffee Husks, December 2015, Pp.283-291

[3] Jemal, J.,2014,In-Depth Investigation Into Engineering Characteristics Of Jimma Soils ,Masters Of Science Thesis Submitted To Civil Engineering Department, Addis Ababa University, Addis Ababa.

[4] Fekerte, A., 2006, "Spectroscopy to Drive Engineering Parameter of Expansive Soil", International Institute for Geo-Information and Earth Observation Enscheda, the Netherlands.

[5] Ethiopian Road Authority, Pavement Design Manual, Flexible Pavements and Gravel Roads, subgrade soil, Addis Ababa, 2002.

[6] Tibebu Solomon 2015 Assessment Of Damages Caused By Expansive Soil On Buildings Constructed In Bahirdar

[7] Gopal Krishna and Natarajan C P (1974), Utilization of Coffee ByProducts. Indian Coffee Vol-38.

[8] Fekerte Arega, Freek van der Meer and Harald van der Werff, 2009 Prediction of Volumetric Shrinkage in Expansive Soils (Role of Remote Sensing), Intechopen.com, Advances in Geoscience and Remote Sensing

[9] http://ethioagp.org/Ethiopian -coffee-exports-to-hit-record-in-2015

[10] GSE, Geology, Geochemistry and Gravity Survey of Jima area., 2012.

[11] Nurela M, 2018, Effects Of Lime And Marble Dust Alloy On An Expansive Subgrade Soil Of Jimma Towns. Jimma University, Jimma. (unpublished)

[12] Aklilu Fikadu (2015), Relationship Between Swelling and Consolidation Characteristics of Expansive Soils Of Galan Town, Addis Ababa

[13] Anwar Abasanbi Abadiga (2010), Assessment of coffee quality and its related problems in Jimma zone of Oromia regional state, Jimma.

[14] Prof. Mahadeva, 2017 "Application of Rice Husk to Improve Engineering Properties of Expansive Soil."

[15] Oliveira and Franca (2015), An Overview of the Potential Uses for Coffee Husks, Brazil. 